means that it is rare that anything is left out, but at the same time, it is often unclear which forces are driving changes or why they happened one way rather than another. Descriptions of details are sometimes excessive and uneven. The book is somewhat repetitive and longer than it needed to be, and the case for connecting globalization to the historical changes involved in the formation of the nation-state is not really explored. If the aim was to construct something akin to what is done by people such as Hannes Lacher and Arrighi and Silver, it really fails; these provide strong diachronic accounts tracing structures over time, whereas Sassen provides parallels that are at best suggestive. Among other things, an entire historical period, and notably the rise of the welfare state, is largely missing or skimmed over in this account.

In addition, Sassen discusses arrangements of territory, authority and rights (such as regimes of private and corporate law), not the concepts themselves. A reader expecting a Foucauldian genealogy or a deconstruction of the concepts as such will be disappointed; indeed, although specific arrangements of these 'elements' are analysed as complex and constructed, the 'elements' themselves come to seem almost primordial. Another problem is that the level of analysis tends to be very institutional - legal and regulatory changes are covered in minute detail, whereas everyday life, which is certainly given an extensive role, is less well covered. These difficulties aside, the book makes a long but stimulating read for scholars interested in understanding the nuances of institutional and spatial changes involved in globalization, beyond the rhetoric and simplifications. Sassen is truly a force to be reckoned within globalization studies.

Andrew Robinson

The University of Nottingham, University Park, Nottingham, UK

\title{
Against recognition
}

Lois McNay

Polity Press, Cambridge, 2008, 232pp., £16.99, ISBN: 978-0745629325

Contemporary Political Theory (2009) 8, 248-250. doi:10.1057/cpt.2008.55

Lois McNay's thoughtful and thought-provoking new book Against Recognition deserves to be widely read. Demonstrating an extensive knowledge and perspicacious understanding of contemporary accounts of the psychology 
and politics of recognition, McNay deploys a modified version of Pierre Bourdieu's notion of habitus, both to point out what she regards as the failings of such accounts and also to suggest a way beyond them.

It must be emphasized straightaway that McNay is not entirely against recognition. She sees value both in its conception of dialogical, situated and practical subjectivity, and in its emphasis on the importance of identity claims in contemporary politics (p. 1). However, McNay objects to a number of general tendencies in contemporary accounts of recognition, focusing in particular on Charles Taylor, Axel Honneth, Seyla Benhabib and Jessica Benjamin. She argues that all of these accounts are based too closely on a Hegelian depiction of the struggle for recognition. In this struggle, at the same time as self and other seek domination over each other, the latent possibility of a reciprocal relationship between the two is also suggested. For McNay, this Hegelian motif leads to a series of interconnected problems. First, it results in an idealized account of the formation of the subject in intersubjective relations, where power is regarded merely as a secondary and distorting effect on such relations and therefore on the subject itself. Hence, these theorists of recognition fail to understand how relations of power are always already present as the individual psyche is formed. Second, these theorists stretch the idea of recognition too far, intending it to serve as both a normative ideal and an analytical tool. But prioritizing the former role means that it fails to achieve the latter. That is to say, by idealizing relations of recognition, the significance of relations of power is crucially underplayed. Third, such theories of recognition fail to understand the intricacies of the links between identity and agency. Assuming that identity is formed in relations of recognition, and that a primal and universal need for recognition leads to effective agency, they do not appreciate the complexities of what McNay, following Bourdieu, calls 'embodied agency'. (For slightly varying formulations of this critique, see pp. 2, 8 and 195-196.)

McNay also identifies a second strand in the contemporary political theory of recognition, thinking in particular of Nancy Fraser, but also in very different ways of Iris Marion Young, Judith Butler and Slavoj Žižek. If the first camp is guilty of subjectivism, because they assume that the subject can be formed without the operation of power, then this second camp is guilty of objectivism, rejecting the Hegelian tradition out of hand and rethinking recognition as an objective form of social injustice. For McNay, this camp encounters the opposite problem to that of the first: because they offer an account of recognition wholly detached from any account of the subject, they fail to develop any account of identity and agency.

In the space available to me here, I cannot assess in detail the specific criticisms that McNay makes of particular accounts of recognition. I can say that her analyses are often spot on, but that her attempts to show how the 
problems she identifies fit her overall diagnosis - that accounts of recognition are either too subjectivist or too objectivist - are sometimes rather strained. In the space that remains, I shall focus instead on the positive account of identity and agency that she offers in her final chapter. This chapter marks a significant shift of focus. Talk of recognition drops away almost entirely, and instead McNay seeks to demonstrate the superiority of her 'socio-centric perspective on the embodied, affectual dimensions of agency for a feminist understanding of gender' (p. 185) over a number of alternative perspectives including those of Butler and Young. This perspective, she claims, will enable her better to analyse issues of gender by revealing 'the systemic ways in which sexual and other inequalities are reproduced' (p. 196). McNay's argument up to this point had led me to hope that this final chapter would deploy a Bourdieusian account of 'embodied agency' to show how the insights of the recognition theorists could be preserved and at the same time their limitations overcome. To be specific, I had hoped for an account of identity and agency, which demonstrated that, although relations of power always shape the formation of the subject, the intersubjective ideal of recognition could nevertheless be maintained. Instead, by entirely giving up on recognition as a normative ideal in order better to analyse relations of power, it is unclear to me what animates McNay's account. The unstated assumption appears to be that power can be dangerous and that the inequality it can produce is wrong. My final suggestion would be that, if this assumption were to be made explicit, and worked up into a full-fledged normative ideal, it might not look entirely unlike recognition theory's ideal of reciprocity.

Simon Thompson

University of the West of England,

Bristol, UK 